Yoshito Yamasaki 1947. Local difference in the occurrence of twin plants and of the chromosome aberrations accompanied, in common wheat. Jap. Jour. Genet. $22: 61 \sim 66$ (With English résumé, p. .64).

\title{
普通小麥に於ける双子並にこれに件う染色 體異數個體發現の地域的差異に關する研究
}

山崎義人

昭和22年5月10日受領

筆者は本問題に閭してかつて本誌第 18 卷第 2 號に其の概要を報告したが，當時向 1,2 の點

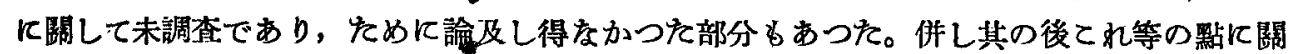
しても略く明かにする事が出來たので前報の詳細と共に之を報告する。

植物の双子に關じて忙, Leeuwenhaeck が 1719年にォレンジの一種について報告して以來 二十数篇の論文が發表せられ，夫《の立場に於て研究せられている事は既に述べねが，双子

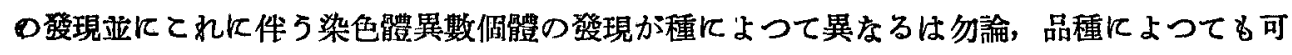
成り著しい相違を示す事は明かで，乙の善異は結局遺傳的に決定せら狄るるのであるらとの 見解が支配的である。しかしをがら，環境も亦或る程度の影響を與えるであろう事は考えら れるとてろで,てれらを明かにする事は生物進化の立埸から重要な意義があると侾えられ る。

筆者は斯る見地に於て普通小麥を材料として次の如き賽驗を行つた。

\section{菑驗材料及び方法}

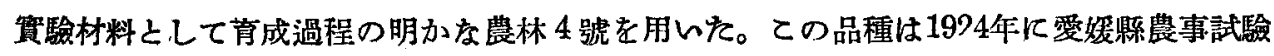
場に於て優勝粸 347 號を母とし，廣島シブレー 3 號を父として交配を行い， $\mathrm{F}_{3}$ - 種子を農林

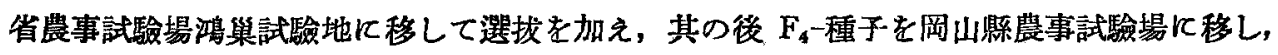
爾來此處に於て選拔育成され，1931年 $F_{7}$ 植物の時代に農林 4 號之命名せられたるのであ

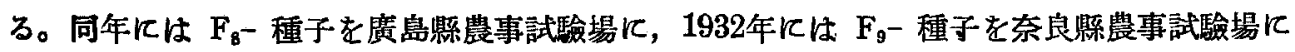

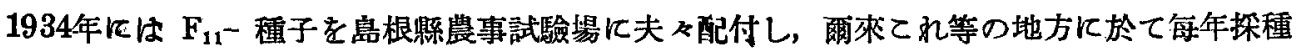
せられたむのである。

以上の 4 地方の网岡山關しては, $1938,1939,1940$, 及び1941年座の $F_{15}, F_{16}, F_{17}$ 及び $F_{18}$ 種子につき，島に關しては1939及ひ1940年産の $F_{16}$ 及び $F_{17}$ 種子につを，奈良に關して は1935, 1938, 1939及び1940年产の $F_{12}, F_{15}, F_{16}$ 及び $F_{17}^{*}$ 種子につき，島根に閣しては1940 及び 1941年産の $\mathrm{F}_{27}$ 及び $\mathrm{F}_{18}$ 種子につをそれぞ礼調查したる外，1941年には更に前年岡山

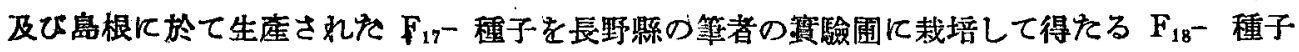
につを調查した。

双子の檢出にば長さ $75 \mathrm{~cm}$, 幅 $45 \mathrm{~cm}$, 深さ $5 \mathrm{~cm}$ のトタシ製容然に種子を一面に並べ適度の水

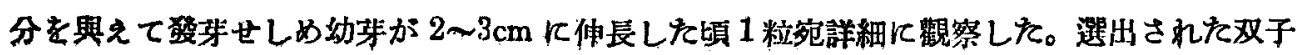


は 1 組宛耕土を入北た小型ペトリー血に假植し，肧乳が略ミ吸收しつくされたる頃てつの分 體に分けて 1 侱軆宛適度の肥料を含んだ耕士を盛つね素燒の小型植木鉢に定植した。

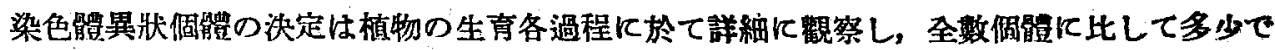
る異狀が認められたものは直ちと根を掘り取つて其の根端をナワンン液で固定に，普通の如 くパラフィン法によつて奶片をつくり， ヘマトキシリン染色によつて染色䯈數を決定した。 從つて異狀の認められなかつた個體は總て全數體として取扱つた。尚染色體數の決定に上る 外，葉の表皮細胞及び氣孔の大さ，花粉の異狀等をも調查し參考とした。

\section{实驗 結 果}

第 1 表は各種子生產地飞於ける年次别の双子能現狀熊を示したるのである。同山に於ては 1938年に0.084\%，1939年に0.085\%，1940年に0.087\%，1941年に0.086\%の䃌現步合を示して レるが，廣島に於ては 1939年に0.027\%，1940年に0.037\%，島根に於ては 1940年に 0.033\%， 1941年に0.031\%，奈良に於ては1935年に0.068\%，1938年に0.068\%，1939年に0.044\%，1940 年に0.033\% 發現し，岡山は他の 3 地方に比して可成り高率の發現步合を示しているのみな ら和微かではあるが年さ共に增加の傾向が籍われ，奈良は逆にや小明かな城少の傾向を示し て的る。

次に染色體異數個體の發現について見るに，第 2 表によつて次の事賽が認められる。郎ち

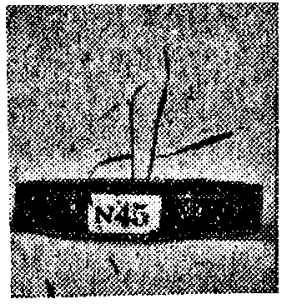

1

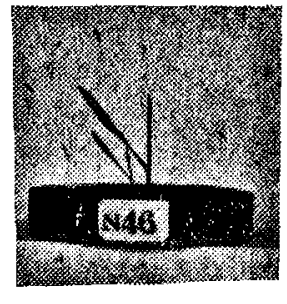

b

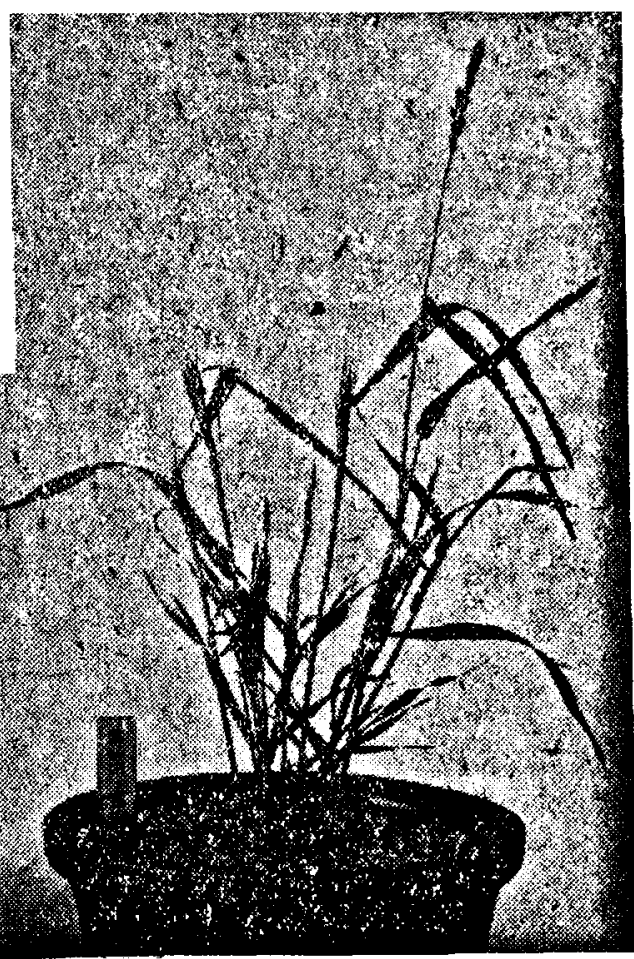

b

2

a

Fig. 1, Seedling stage of the twin having $2 n-1(41)-n-1(20)$ chromosomes. a, left : $n-1=20$; right : $2 n-1=41, b, 42-42$.

Fig. 2, The abnormal twin at earing stage a, $n-1=20, b, 2 n-1=41$ 


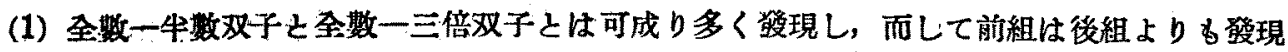

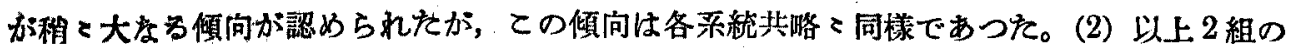
外に, 2n-1-n-1 双子が1935年に奈良產種子に於て 1 倜膘（Fig. 1 及び 2)，1940年に岡山産

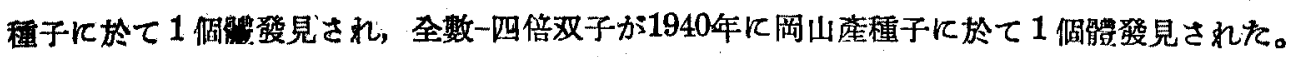
(8) 全数一全數双子以外の双子の全双子に對する步合を見るに，同山に䋇ては 1939 年に 10.3 \%，1940年に11.1\%，1941年に11.2\%であつたが，廣島に於ては1939年及び1940年共に6.7\% 具根に於ては1940年に9.4\%，1941年に8.6\%，渏良に於ては 1935 年に9.6\%，1939年に8.5\%，

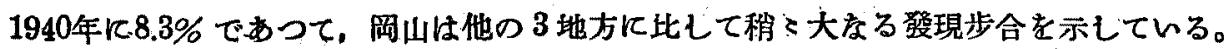

以上の結果は種子の生産地によつて双子及びてれに件う染色體異數個體の發現に苃異のす

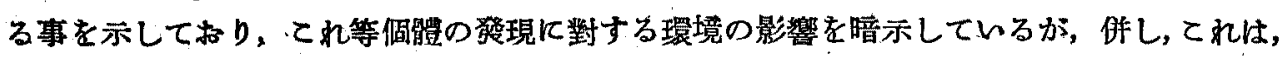

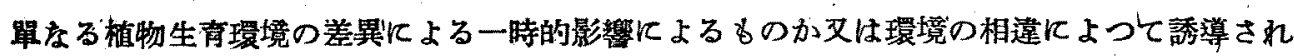
た遗傅的差異によるるかか倘不明である。そこで, 筆者は1940年に岡山及び島根より取寄 せた $\mathrm{F}_{17}$-種子をを1941年に長野縣桔梗ヶ原に於ける賽驗圑に於て同一條件の下に栽培し， $F_{18}$

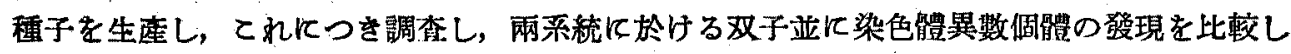

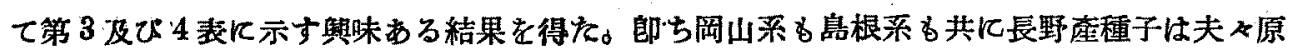

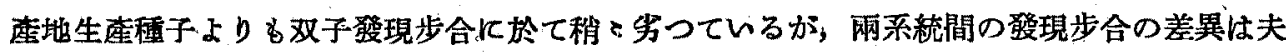

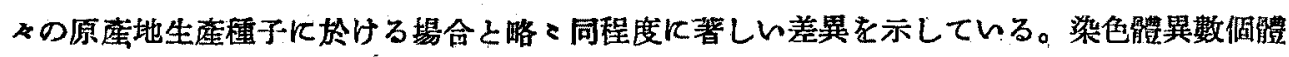

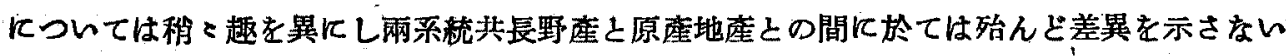

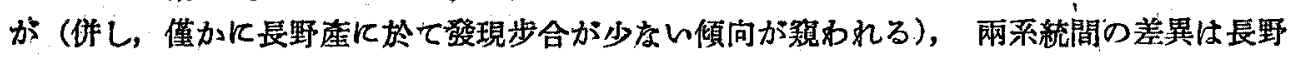

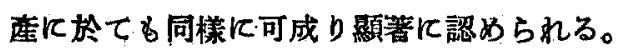

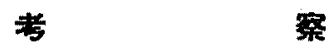

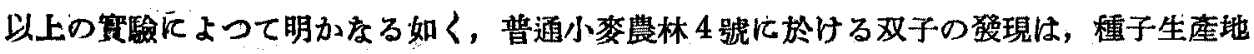

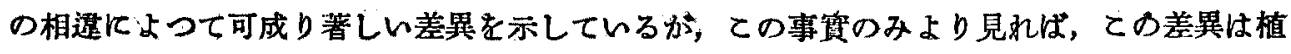

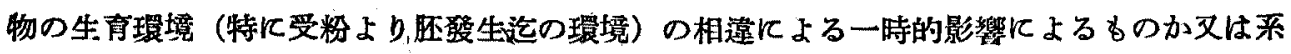
梳間の遗传的差異によるるのか忏明かでない。併し，岡山係と島根系とを長野に於て同一條

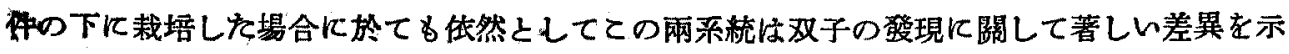
す事れより見れば，上迅の如を顯著な地域的差異は瞢境の相違による一時的影響ではなくし て主よして遗傳的差異によるるのと結論せざるを得をい。併しながら，第3表によつて明か

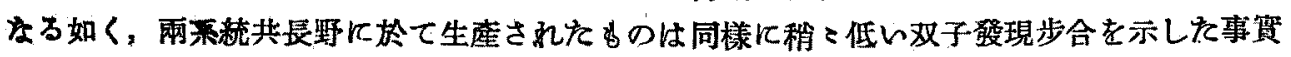

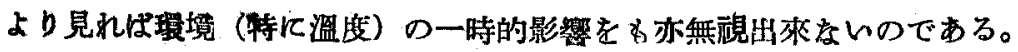

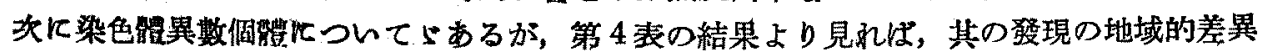

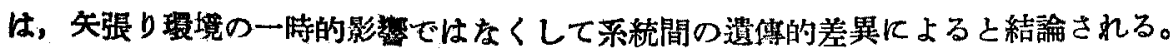

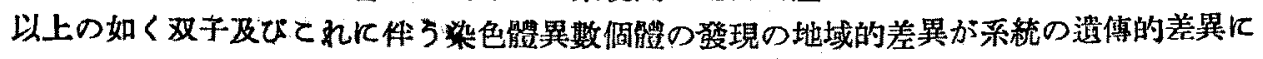
よるとすれば，ての遗傳的差異は同一品種に出發した各系統に㮩て如何にして生じたかか問 通となるがてれについては次の二のの事唡が将えられる。

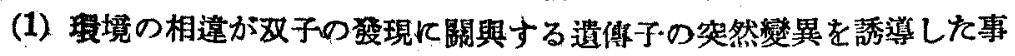

（2）晨林 4 號は $F_{8}$ 乃至 $F_{11}$ 一、種子の時代に岡山より各地に移されたのであるが，ての時

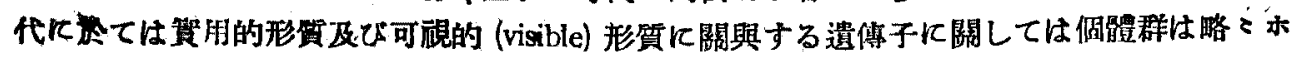

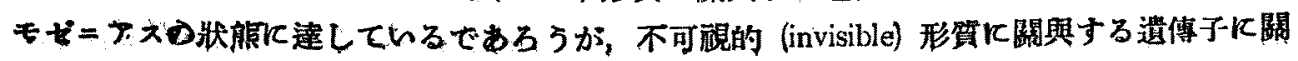


しては倘へテロぜニアス狀態に牫されていると考えられる。故に，てれが異㧼境に移される

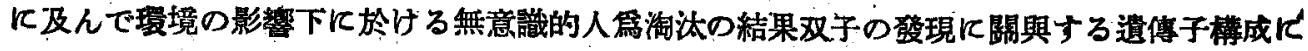
差異を生した事

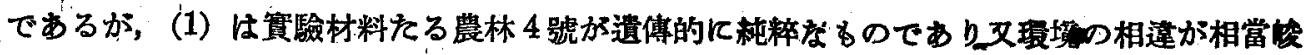

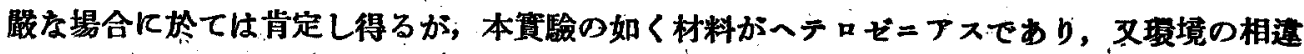

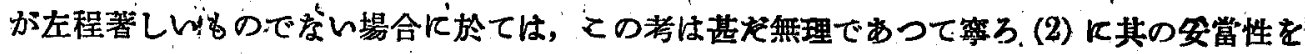

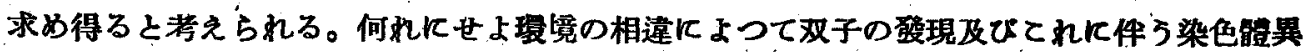
數倜體の發現に關して遺傳的差異を生ぜし事賽は生物進化の立場より一つの興味する問題を 提供するるのと思われる。

倘本問題に閣しては他の植物に關して實驗を施行中でするがての結果を得て他日更に詳論 したんと思5。

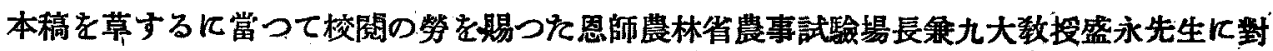
し深謝の意を表する。

\section{文}

Bergstrōm, I. 1938. Hereditas 24 : 210. Harland, S, C. 1936. - Journ. Feredity 27 : 229. Kąppert, H. 1933. Biol. Zbl. 53 :276. Kihara, H. 1986. Agr. and Hort. 11 : 1425. — 1940, Agr. and Hort. 15 : 1096. - 1941. Bot. Mag. 54. -1942. Rep. Kihara Inst. Biol. Res. 1 : 3. Lamm, R. 1938. Hereditas 24': 391. Müntzing, A. 1936. Tlereditas $21: 263$. - 1937. Cytologia Fujii Jub. vol. 211. — 1938. Hereditas $24: 487$. - and Prakken, R. 1940. Hंereditas 26:463. Namikawa, S. and Kawakami, J. 1934. Proc. Imp. Acad. $\times(10)$ : 668.' Ramiah, k., Parthasarathi, N.and Ramanujam, S. 1933. Current Sci. Mysore 1. 1935. Indian Journ, Agr. Sci. 5. Sengbusch, R. v. 1940. Züchter 12 : 185. Skkausted, A. 1939. Compt. Rend. Trav. Lab. Carisberg Sér. Phyșiol. 22 : 427. Webber, J. M. 1938. Journ. Agr. Res. 57 : 155. Yamamoto, Y. 1936. Cytologia 7:431. 1936. Bot. Mag. 50. - 1937. Kagaku 7 : 147. Yamasaki, Y. 1937. : Jap. Jour. Gen: $13: 323$. - and Ishihara, M. 1942. Jap. Jaurn, Gen. $18: 121$.

\section{Résumé}

1 The occurrence of twin plants and of the chromosome aberrations accompanied was exmined on the seeds of Norin No. 4, produced in the following localities: Okayama, Hiroshima, Shimane and Nara.

a) The chromosome aberration types detected in the twin plants were as follows : 42-21, 41-20, 42-63 and 42-84 (Table 2).

b) The frequency of twinning and of the occurrence of these chromosome aberrant halves were obviously greater in Okayama seeds than in the seeds from other localities (Table 1 \& 2).

2 The seeds obtained from Okayama and Shimane were sown, in the fall of 1940 , in Nagano, and the seeds produced in the following spring were examined.

a) The frequency of twinning and of the occurrence of the chromosome aberrant halves were again greater in Okayama-line than in Shimane-line (Table 3 \& 4).

b) From these facts it may be concluded that the laocal difference of the frequency of twinning and of the occurrenec of the chromosome aberrant halves may be due to genetical differences which were induced by environmental disparity in these loçalities, 
Table 1. Frequency occurrence of twin plants from the seeds of different sources. (Norin No. 4)

\begin{tabular}{|c|c|c|c|c|c|c|c|c|c|c|c|c|c|c|c|}
\hline 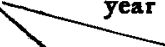 & \multicolumn{3}{|c|}{1935} & \multicolumn{3}{|c|}{1938} & \multicolumn{3}{|c|}{1939} & \multicolumn{3}{|c|}{1940} & \multicolumn{3}{|c|}{1941} \\
\hline Source It & $\begin{array}{l}\text { No. of } \\
\text { seeds } \\
\text { examined }\end{array}$ & $\begin{array}{c}\text { No. of } \\
\text { twin } \\
\text { plants }\end{array}$ & $\%$ & $\begin{array}{l}\text { No. of } \\
\text { seeds } \\
\text { examined }\end{array}$ & $\begin{array}{l}\text { No. of } \\
\text { twin } \\
\text { plants }\end{array}$ & $\%$ & $\begin{array}{c}\text { No. of } \\
\text { seeds } \\
\text { examined }\end{array}$ & $\begin{array}{l}\text { No. of } \\
\text { twin } \\
\text { plants }\end{array}$ & $\%$ & $\begin{array}{l}\text { No. of } \\
\text { seeds } \\
\text { examined }\end{array}$ & $\begin{array}{c}\text { No. of } \\
\text { twin } \\
\text { plants }\end{array}$ & $\%$ & $\begin{array}{c}\text { No. of } \\
\text { seeds } \\
\text { examined }\end{array}$ & $\begin{array}{l}\text { No. of } \\
\text { twin } \\
\text { plants }\end{array}$ & $\%$ \\
\hline Okayama & - & 7 & - & $\mathbf{3 2 , 2 4 0 !}$ & 27 & 0.084 & 67,930 & 58 & 0.085 & 103,130 & 90 & 0.087 & 314,286 & 268 & 0.086 \\
\hline Hiroshima & & - & - & - & - & - & 55,260 & 15 & 0.027 & 121,050 & 45 & 0.037 & & - & - \\
\hline Shimane & . & - & - & - & - & - & - & 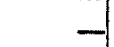 & - & 96,550 & 32 & 0.033 & 417,538 & 128 & 0.031 \\
\hline Nara & 183,960 & 125 & 0.068 & 77,613 & 53 & 0.068 & 105,850 & 47 & 0.044 & 36,500 & 12 & 0.033 & & - & - \\
\hline
\end{tabular}

Table 2. Frequency occurrence of twin plants of various chromosomal conditions (Norin No. 4)

\begin{tabular}{|c|c|c|c|c|c|c|c|c|c|c|}
\hline \multirow{2}{*}{ Year } & \multirow{2}{*}{ Source } & \multirow{2}{*}{$\begin{array}{l}\text { No. of } \\
\text { twin } \\
\text { plants } \\
(x)\end{array}$} & \multicolumn{6}{|c|}{ Chromosomal constitutions of twins } & \multirow{2}{*}{$\begin{array}{c}b+c+d+e \\
(y)\end{array}$} & \multirow{2}{*}{$\frac{y}{x} \times 100$} \\
\hline & & & $\begin{array}{c}42-42 \\
\text { (a) }\end{array}$ & $41-20$ & $\underset{(c)}{42-21}$ & $\begin{array}{c}42-63 \\
\text { (d) }\end{array}$ & $\underset{\text { (e) }}{42-84}$ & undecided* & & \\
\hline 1935 & Nara & 125 & 88 & 1 & 6 & $\mathbf{5}$ & - & 25 & 12 & 9.6 \\
\hline 1938 & $\begin{array}{l}\text { Okaya ma } \\
\text { Nara }\end{array}$ & $\begin{array}{l}27 \\
53\end{array}$ & - & - & - & - & - & - & - & - \\
\hline 1939 & $\begin{array}{l}\text { Okayama } \\
\text { Hiroshima } \\
\text { Nara } \\
\end{array}$ & $\begin{array}{l}58 \\
15 \\
47\end{array}$ & $\begin{array}{l}47 \\
13 \\
39\end{array}$ & $\begin{array}{l}- \\
- \\
-\end{array}$ & $\begin{array}{l}4 \\
1 \\
2\end{array}$ & $\begin{array}{r}2 \\
- \\
2\end{array}$ & $\begin{array}{l}- \\
- \\
\end{array}$ & $\begin{array}{l}5 \\
1 \\
4 \\
\end{array}$ & $\begin{array}{l}6 \\
1 \\
4 \\
\end{array}$ & $\begin{array}{r}10.3 \\
6.7 \\
8.5\end{array}$ \\
\hline 1940 & $\begin{array}{l}\text { Okayama } \\
\text { Hiroshima } \\
\text { Shimane } \\
\text { Nara }\end{array}$ & $\begin{array}{l}90^{* *} \\
45 \\
32 \\
12^{* *}\end{array}$ & $\begin{array}{l}74 \\
37 \\
29 \\
11\end{array}$ & $\begin{array}{r}1 \\
- \\
-\end{array}$ & $\begin{array}{r}5 \\
2 \\
1 \\
-\end{array}$ & $\begin{array}{l}3 \\
1 \\
2 \\
1\end{array}$ & $\begin{array}{r}1 \\
- \\
- \\
-\end{array}$ & $\begin{array}{r}6 \\
5 \\
- \\
-\end{array}$ & $\begin{array}{r}10 \\
3 \\
3 \\
1\end{array}$ & \begin{tabular}{r|}
11.1 \\
6.7 \\
9.4 \\
8.3
\end{tabular} \\
\hline 1941 & $\begin{array}{l}\text { Okayama } \\
\text { Shimane }\end{array}$ & $\begin{array}{l}268 \\
128\end{array}$ & $\begin{array}{r}204 \\
94\end{array}$ & - & $\begin{array}{r}17 \\
6\end{array}$ & $\begin{array}{r}13 \\
5\end{array}$ & - & $\begin{array}{l}34 \\
33\end{array}$ & $\begin{array}{l}30 \\
11\end{array}$ & $\begin{array}{r}11.2 \\
8.6\end{array}$ \\
\hline
\end{tabular}

* Owing to their premature death, the chromosomal conditions of the twins were not determined.

** One of these plants is a triplet. 
Table 8. Frequency occurrence of twin plants in Nagano comparing with that in original localities (Norin Nc

\begin{tabular}{|c|c|c|c|c|c|c|}
\hline \multirow{3}{*}{ Source } & \multicolumn{6}{|c|}{ Twin plants from the seeds produced } \\
\hline & \multicolumn{3}{|c|}{ in original locality (1941) } & \multicolumn{3}{|c|}{ in Nagano (1941) } \\
\hline & $\begin{array}{l}\text { No. of seeds } \\
\text { examined }\end{array}$ & $\begin{array}{l}\text { No. of twin } \\
\text { plants }\end{array}$ & $\%$ & $\begin{array}{c}\text { No. of seeds } \\
\text { examined }\end{array}$ & $\begin{array}{l}\text { No. of twin } \\
\text { plants }\end{array}$ & $\%$ \\
\hline Okayama & 314,286 & 268 & 0.086 & 411,016 & 244 & 0.059 \\
\hline Shimane & 411,538 & 128 & 0.031 & 397,506 & 85 & 0.021 \\
\hline Total & 725,824 & 396 & 0.054 & 808,522 & 329 & 0.041 \\
\hline
\end{tabular}

Table 4. Frequency occurrence of twin plants with deviating chromosome numbers in Nagano comparing with that in original localities (Norin No. 4)

\begin{tabular}{|c|c|c|c|c|c|c|c|c|c|c|c|c|c|c|}
\hline \multirow{4}{*}{ Source } & \multicolumn{14}{|c|}{ Twin plants with deviating chromosone numbers } \\
\hline & \multicolumn{7}{|c|}{ in original locality (1941) } & \multicolumn{7}{|c|}{ in Nagano (1941) } \\
\hline & \multirow{2}{*}{$\begin{array}{l}\text { No. of } \\
\text { twin } \\
\text { plants } \\
(x)\end{array}$} & \multicolumn{4}{|c|}{ No. of twin plants with } & \multirow{2}{*}{$\begin{array}{c}b+c \\
(y)\end{array}$} & \multirow{2}{*}{$\frac{y}{x} \times 100$} & \multirow{2}{*}{$\begin{array}{l}\text { No. of } \\
\text { twin } \\
\text { plants } \\
(x)\end{array}$} & \multicolumn{4}{|c|}{ No. of twin plants with } & \multirow[b]{2}{*}{$\begin{array}{c}b+c \\
(y) \\
\end{array}$} & \multirow{2}{*}{$\frac{y}{x} \times 100$} \\
\hline & & $\begin{array}{c}42-42 \\
\text { (a) }\end{array}$ & $\begin{array}{c}42-21 \\
\text { (b) }\end{array}$ & $\begin{array}{c}42-63 \\
(c)\end{array}$ & undecided * & & & & $\begin{array}{c}42-42 \\
(a)\end{array}$ & $\begin{array}{c}42-21 \\
\text { (b) }\end{array}$ & $\begin{array}{c}42-63 \\
(\mathrm{c})\end{array}$ & undecided * & & \\
\hline Okayama & 268 & 204 & 17 & 13 & 34 & 30 & 11.2 & 244 & 190 & 14 & 12 & 28 & 26 & 10.7 \\
\hline Shimane & 128 & 94 & 6 & 5 & 23 & 11 & 8.6 & 85 & 68 & 3 & 4 & 10 & 7 & 8.2 \\
\hline
\end{tabular}

Qwing to their premature death, the chromosomal Conditions of the twins were not determined. 